\title{
PPDR Information Systems - A Current Status Review Report
}

\author{
Dimitrios Kavallieros ${ }^{*}$, Stefanos Malliaros, Ioannis Daniilidis, George Leventakis, Vasileios Grizis \\ Center for Security Studies (KEMEA), Greece
}

Copyright $\bigcirc 2015$ by authors, all rights reserved. Authors agree that this article remains permanently open access under the terms of the Creative Commons Attribution License 4.0 International License

\begin{abstract}
Public safety organizations include emergency and law enforcement agencies, fire departments, rescue squads, and Emergency Medical Services (EMS). In response to increasing threats of terrorism and natural disasters, safety and security personnel must overcome technology barriers to enhance their efficiency, especially in the neuralgic section of information exchange. Limited availability of information hinders the response time and decision making process. Efficient communications supported by interoperable technology are vital to the situational awareness, scalability, and effectiveness of incident response. This paper's prime objective is the review of available information systems than can be used to support and assist security agencies.
\end{abstract}

Keywords Information Systems, Disaster Management, Disaster Preparedness, Early Warning Systems

\section{Introduction}

The frequency and intensity of natural or man-induced disasters have increased over the last few decades, accounting for great cost of lifes and commodities. Public Protection and Disaster Relief (PPDR) agencies, also known as first responders, are the primary forces that deal with incident response. These agencies operate in a hierarchical structure where high level officers take the decisions and coordinate the actions of the operation.

A key parameter to an incident response is the fast transmission and processing of data derived from the field of operation. Although communication systems are an integral part of PPDR agencies, interoperability between the different PPDR communication systems may not be feasible in most cases. This radically hinters the decision making process and the effectiveness of the human resources.

This paper reviews the Information Systems known to support PPDR agencies in the field or can help prevent or predict an upcoming disaster. This is the first paper that reviews all the known information systems presently utilized.

\section{Information Systems}

\subsection{The European Forest Fire Information System (EFFIS)}

EFFIS supports the prevention, preparedness, post-fire evaluation and firefighting of wildfires in European level, it became operational in 2000 by the Joint Research Centre (JRC) and the Directorate General for Environment (DG ENV). EFFIS derived from the action taken by two work groups created in 1998, the first was JRC's research group while the second was the collaborative initiative of DG ENV and JRC. The main goal of the first group was to develop and utilize mechanisms to map the burnt area and calculate the forest fire danger while the second one was working as an advisory group on the development of the aforementioned mechanisms [1].

EFFIS supports an on-line system, a database regarding wildfires in EU and produces reports on wildfires, in annual base. During the fire season, EFFIS produces fire forecasts for up to six days, twice every day these forecasts are processed through emails in the relative departments and civil protection agencies of the Member States of EU. The "up-to-date situation" interface provides real time information (e.g. hot spots maps) during the fire season as well "as tools providing maps of fire danger anomalies and absolute ranking based on the fire danger index adopted" [2]. Moreover, EFFIS offers several applications such as Current Situation, Long-term fire weather forecasts, Fire History and Fire news, as explained below.

Current Situation produces fire forecasts up to six days during the fire season, for Europe and the Mediterranean area. The maps regarding the hot spots and fire perimeter are updated in daily basis. However, this application has some drawbacks; namely, the location of a hotspot in the map is accurate within a distance of $1.5 \mathrm{~km}$, the MODIS sensors cannot detect exclusively fires and hotspots but also any other heat source; furthermore it might not detect small fires 
or fires covers by smoke or clouds. Therefore, care must be taken while using this application [3].

Long-term fire weather forecasts offers two forecast functionalities for European and Mediterranean areas; these are:

- Seasonal forecast of temperature and rainfall anomalies, an experimental product which produces forecast maps for the two succeeding months except during the fire season where it produces monthly forecast maps.

- Monthly forecast of temperature and rainfall anomalies, also an experimental tool producing forecast maps for two weeks in advance in regular season and every week during the fire season.

Fire History provides access to all fire incidents occurred from 1980 until 2011 in Europe. All the relevant information are stored in the European Fire Database [3].

Through the Fire News application the users can search for news regarding wildfires based on the location and the date they are interested for.

EFFIS is composed of five modules, the Fire Danger Forecast, the Active Fire Detection, the Rapid Damage Assessment (RDA), Fire Damage Assessment and the European Fire Database.

The Fire Danger Forecast currently in test mode, produces daily maps for up to six days spanning over an eight month period, from the $1^{\text {st }}$ of March until the $31^{\text {st }}$ of October. As an input it uses forecast data from the Meteo-French (MF) and the German meteorological services (DWD).The categorization on the maps produced by the Fire Danger Forecast are composed by six classes as depicted in table 1 , with a spatial resolution of about $10 \mathrm{~km}$ (MF data) and $36 \mathrm{~km}$ (DWD data) [4].

Table 1. Fire Danger Forecast Classes [4]

\begin{tabular}{|c|c|}
\hline Fire Danger Classes & $\begin{array}{c}\text { FWI ranges } \\
\text { (upper bound excluded) }\end{array}$ \\
\hline Very low & $<5.2$ \\
\hline Low & $5.2-11.2$ \\
\hline Moderate & $11.2-21.3$ \\
\hline High & $21.3-38.0$ \\
\hline Very High & $38.0-50.0$ \\
\hline Extreme & $>=50.0$ \\
\hline
\end{tabular}

The Active Fire Detection module identifies active fires based on the hotspots produced by MODIS sensor and was implemented in 2007 supporting the Monitoring and Information Center (MIC). Information regarding active fires are updated on a daily basis and if necessary every three hours from the acquisition time of the images produced by the MODIS sensors. In order to minimize false alarms a knowledge based algorithm has been implemented accounting the land cover categories of the surrounded area, the confidence level of the hotspot and the distance between the hotspot and metropolitan areas as well as the distance with man-made surfaces [5].

$\boldsymbol{R D} \boldsymbol{A}$ was installed in 2003 to map the burned areas during the fire season (June-September) based on the images produced in daily bases from the MODIS sensors. RDA takes into account only burned areas by fires equal or larger than 40 ha. [6].

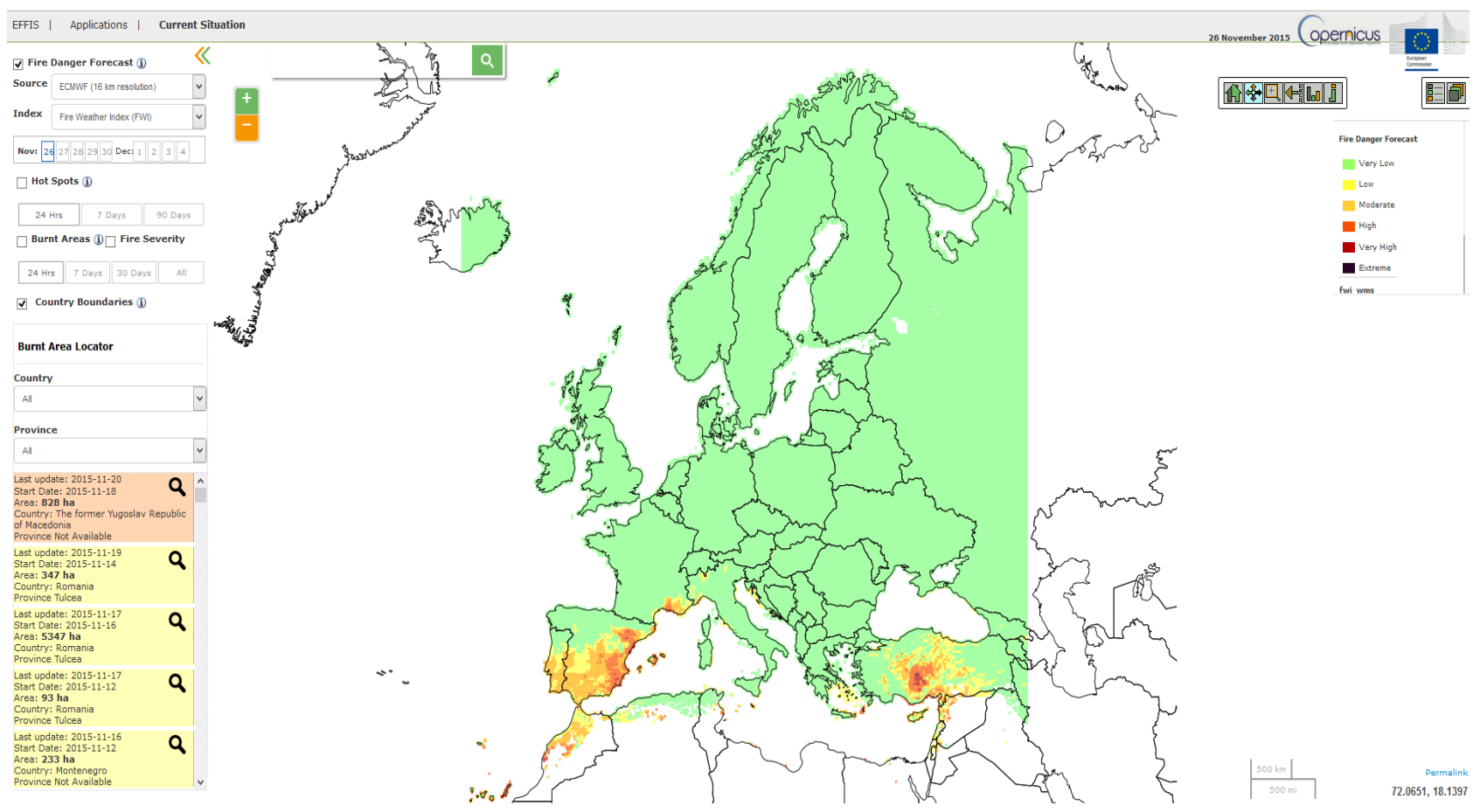

Figure 1. EFFIS Current Situation Interface 
The Fire Damage Assessment module is mapping the burned areas due to wildfires at the end of the fire season, based on images produced by Wide Field Sensor (WiFS) of $180 \mathrm{~m}$ ground spatial resolution. However, the image resolution was not sufficient and even though it was improved at $32 \mathrm{~m}$ ground spatial resolution, the development on $R D A$ module has been postponed for the time being, awaiting further input [7].

The European Fire Database contains data and information regarding forest fires provided by twenty one EU Member States on annual bases since 2004 [8].

Further to the aforementioned, the EFFIS team is currently developing two additional modules, the Post-fire vegetation regeneration and the Post-fire soil risk. Once the Post-fire vegetation regeneration module is complete, EFFIS will be able to evaluate the vegetation recovery in areas damaged by fires; this will be achieved by comparing images, acquired by satellites of the area, before and after the fire. The Post-fire soil risk module will estimate any potential soil loss and corrosion in burnt areas and pin pointing the areas requiring urgent prevention actions [9].

\subsection{European Flood Awareness System (EFAS)}

In response pf the floods in Danube and Elbe in 2002 EC developed EFAS, the pan-European early flood warning system which became part of the Emergency Management Service of Copernicus Initial Operations in 2011 after it was tested in real time conditions for five years, from 2005 to 2010; this Information System has been fully operational since October of 2012. EFAS's three main operational goals are, i) to add value in early flood forecasting products and hydrological services, ii) to build a network of operational hydrological services in Europe and iii) to provide early warning pan-European overview products (e.g. maps) for forecast floods up to fifteen days in advance and for ongoing floods [10].

EFAS apart from providing information about ongoing and forecast floods it created a prototype archive which is available to the public, while real-time monitoring is only accessible to registered users, allocated from the respective national/regional forecasting centers; the latest can check for forecasts every day, using the Web interface of EFAS by providing their credential [11].

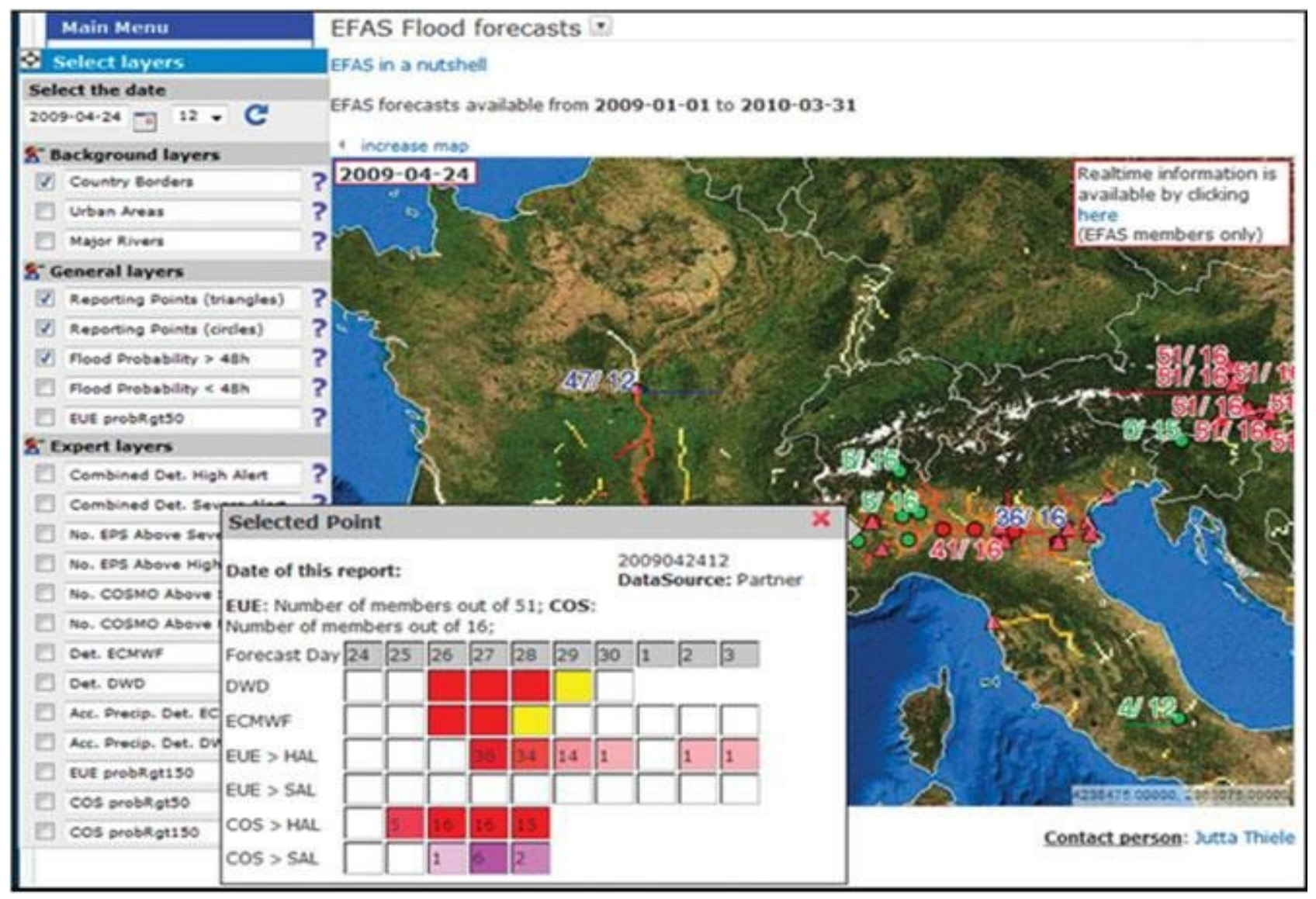

Figure 2. EFAS flood forecasts interface [11] 
Based on Bartholmes et al [12], the two most important flood alerts of EFAS are:

- "Severe alert level (SAL) threshold:

- Very high possibility of flooding, potentially severe flooding expected

- High alert level (HAL) threshold:

- High possibility of flooding, bankful conditions or higher expected

The data produced from the European Centre for Medium-Range Weather Forecasts (ECMWF) and the German Weather Service (DWD) provide input to EFAS as well as the Ensemble Prediction Systems (EPS) from ECMWF and from the Consortium for Small-scale Modeling (COSMO). The EPS form ECMWF provide the medium-range forecasts up to fifteen days globally, while the EPOS from COSMO provide forecasts up to five days for Europe.

\subsection{Global Flood Awareness System (GloFAS)}

GloFAS is the result of the synergy of JRC with ECMWF of a system alerting of potential flooding events globally [13]. GloFAS utilizes an operational ensemble of stations which exchange near-surface meteorological parameters; it uses datasets including climatology data in order to successfully calculate the possibility of flooding events on daily basis.
Figure 3 depicts the distribution of stations used by GloFAS. Primarily, GloFAS uses the Variable resolution Ensemble Prediction System (VarEPS) which comprises 51 global forecasts sources with to provide a flood prediction range of $32 \mathrm{~km}$ for 10 days [14]. Furthermore, GloFAS uses global atmospheric analysis which is provided by the ECMWF; the atmospheric monitoring is performed in $80 \mathrm{~km}$ range and is updated in near real-time. Based on aforementioned inputs, GloFAS simulates for example, the river discharge with the Lisflood hydrological model that supports daily forecasting of regions of $10 \mathrm{~km}$ in range. Two types of simulations are conducted in daily basis; these are:

- Daily simulations using the latest VarEPS predictions leading to 51 possible results of stream flows for the selected forecast horizon.

- Using input data since 1990, a climatological simulation derives the daily and annual maxima and thresholds that will be set up for the detection of potential flooding.

One of the most important features of GloFAS is the early warning system which is running operationally since July 2011. A case study has been performed based on the 2010 Pakistan floods which covered approximately one-fifth of the total land area of Pakistan. The prediction of flooding from GloFAS was at $100 \%$ percentage accuracy on 28 of July 2010 . Hence, early warning is critical in order to prevent or mitigate the risks that rise with a flooding event.

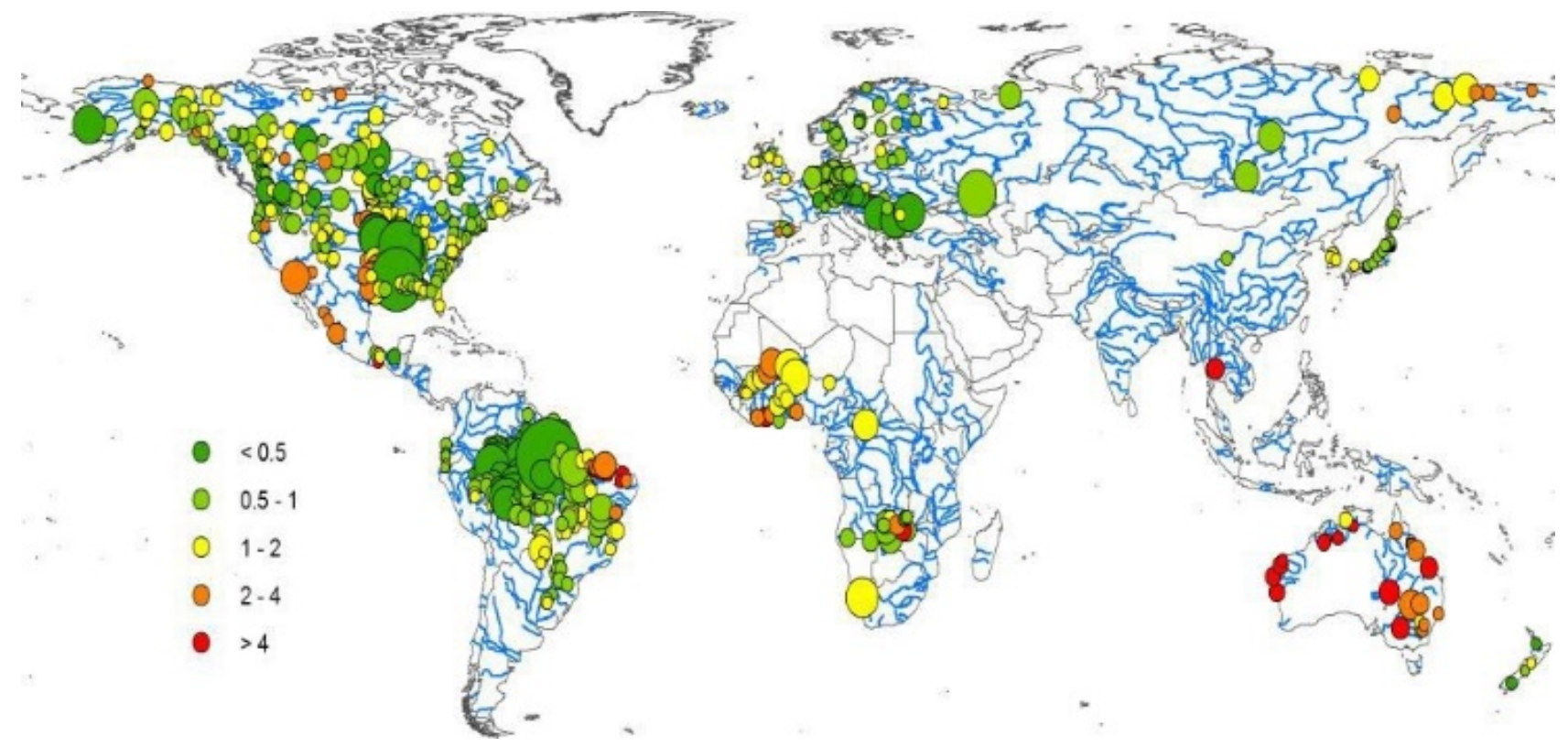

Figure 3. Coefficient of variation of the estimation residuals for the 620 stations considered. Circle size is proportional to the upstream area of the river station [14] 


\subsection{Global Disaster and Coordination System (GDACS)}

GDACS is a web-based system, created in 2004 through the collaboration of the United Nations and European Commission. The aim of GDACS is to fill the information as well as the coordination gap during the early phase of a natural disaster (e.g. Earthquakes, floods, tropical cyclones and tsunamis). The GDACS website consists of the following information systems and coordination tools; the GDACS Disaster Alerts, The Virtual On-Site Operations Coordination Center (OSOCC) and the GDACS Satellite Mapping and Coordination System (SMCS) [16, 17].

The GDACS Disaster Alerts are automatically generated based on specific algorithms and available data to alert of forthcoming disasters. It has four different alert types, White, Green, Orange and Red which are calculated based on specific risk indicators. The main risk indicators which are taken into account are the Severity of the disaster, the Population and the Infrastructure that will be affected by the upcoming disaster and the Vulnerability of the country that will be affected. Moreover, if an alert is generated the subscribed users are notified via Email and SMS [17, 18].

The following table depicts the four alert types generated by GDACS,

Table 2. GDACS alert types

\begin{tabular}{|c|c|c|}
\hline Alert Type & Disaster Level & International Assistance \\
\hline White & Minor & Not required \\
\hline Green & Moderate & Not likely to be required \\
\hline Orange & Potential local & Might required \\
\hline Red & Potential severe & Expected \\
\hline
\end{tabular}

Furthermore, it is important to emphasize that the accuracy of the alerts is as accurate as the available information regarding the population and infrastructure of the area that will be affected.

The Virtual OSOCC is an online platform, designed to exchange/share structured information in real time and to facilitate the cooperation and coordination of the response teams during the first phase of a disaster. Furthermore, it can also assist decision making process and the analysis of the available information. Access to the platform is granted only to disaster managers working either for governments or response organizations $[16,17]$.

The users of the GDACS's SMCS communication and coordination platform can monitor any mapping activities and inform the stakeholders, during the course of a disaster, using available satellite images and maps provided by numerous organizations such as the United Nations Operational Satellite Applications Programme (UNOSAT).

\subsection{Cisco Open Platform for Safety and Security (COPPS)}

COPSS is Cisco's approach to fulfill the needs of the security agencies which enables them to develop solutions for their needs, while ensuring flexibility to the adoption of new-technologies, real-time decision making, and networked command and control. COPSS can be applied to several security fields such as crisis management, urban security, border control, secure public transportation and much more.

COPSS is an architecture framework consisting of six major components: a) Command and control; b) Mission-critical networks; c) Incident Collaboration; d) Sensing and Actuation; e) Mobile force; and f) Citizen-Authority interaction [19]. These components can be combined in order to provide ubiquitous network connectivity by using different communication technologies. For example, the mission-critical network is based on the IP protocol and the access methods which can be used are: a) TETRA; b) WiMax; c) Wi-Fi; d) 3G; and e) satellite communication technologies. Apart from the network connectivity, interoperability is one of the most important functionalities to increase the effectiveness of the Public Protection and Disaster Relief agencies. The incident collaboration building block enables the security teams to communicate using different technologies including IP and analog or digital radio, instant messaging, data and video communications [19].

In order to enhance the decision making process and respond to emergency incidents, data inputs from multiple entities are required. COPSS uses a fusion center which processes data from multiple sources, monitors the input data, and automatically responds in a case of emergency. It is notable that sensors, biometric technologies for human identification, object identification, real-time video analytics are some of the inputs that are supported by COPSS. Fleet management is another important parameter which has been taken into account [20]. Mobile terminals and vehicle computing devices, are supported which can ensure the effectiveness of the human resources in the field. 


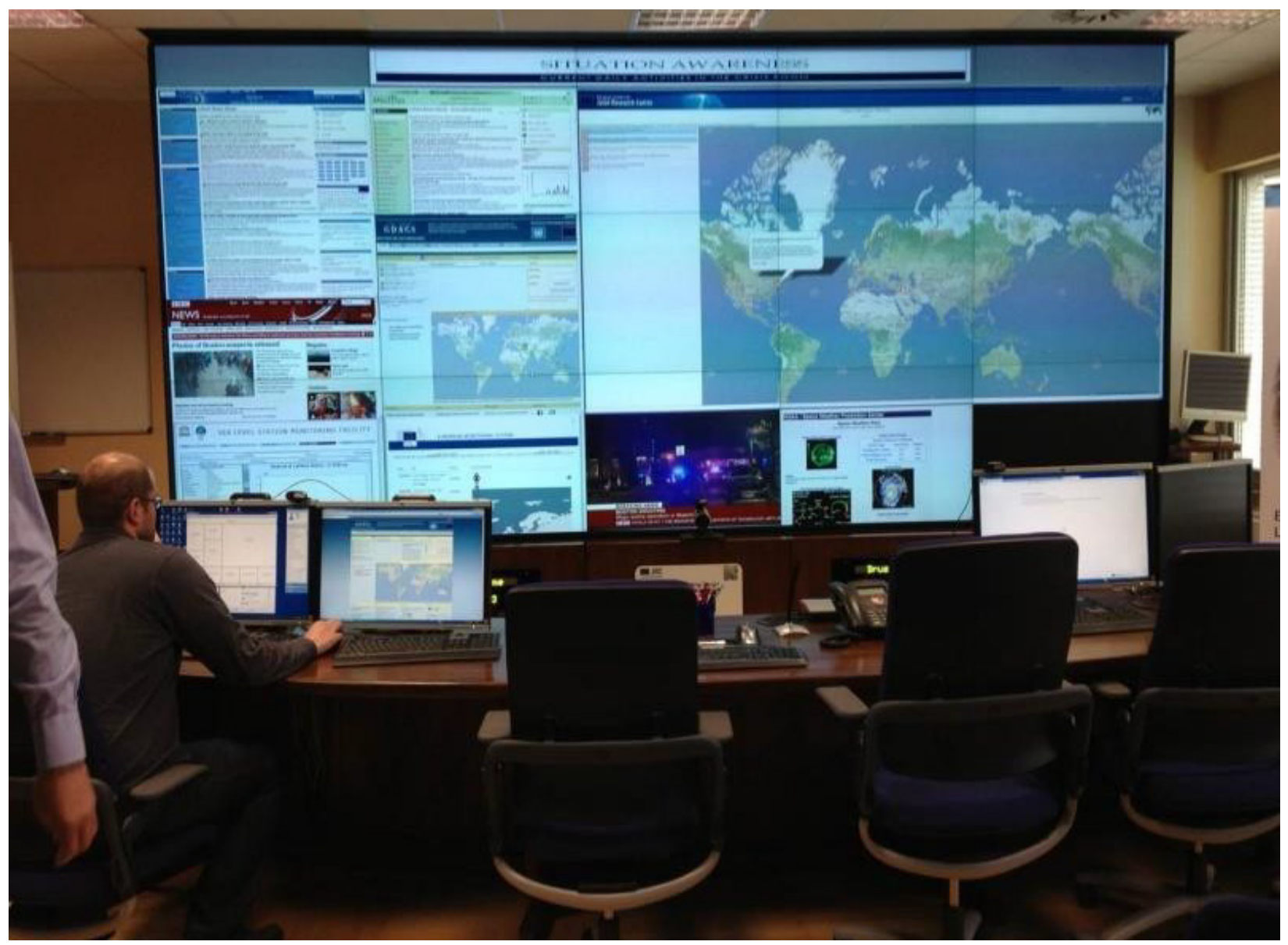

Figure 4. Information Systems in control room

\subsection{Indian Ocean Tsunami Warning System (INCOIS)}

The INCOIS was decided to be deployed after the 2004 Indian Ocean Tsunami which cost the lives of around 280.000 people [21]. The system started operating at 2006 consisting of 25 seismographic stations relaying information to 26 national tsunami information centers, as well as 6 Deep-ocean Assessment and Reporting of Tsunami buoys [22]. INCOIS is accessible through the system's web interface (figure 3) and people can be enrolled in order to receive emails or SMS regarding tsunami warnings. INCOIS, in 2012, alerted the Indian islands on Andaman and Nicobar for a tsunami within 8 minutes of the initial earthquake.

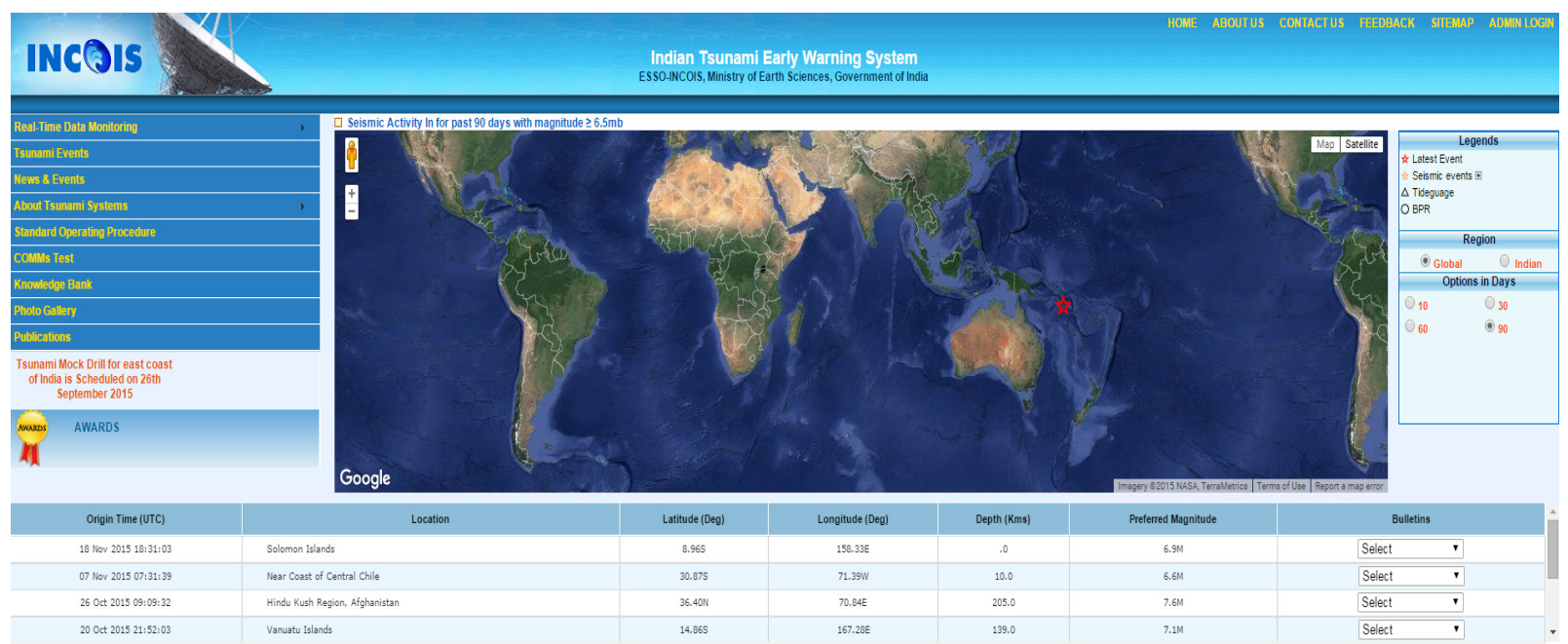

Figure 5. Indian Ocean Tsunami Warning System 
INCOIS comprises of three subsystems, the Seismic, the Tide Gauge and the Bottom Pressure Recording (BPR), which can be used in order to create tsunami models based on real-time data.

The Seismic subsystem measures earthquakes based on their Magnitude and it consists of 25 seismographic stations [23].

The Tide Gauge subsystem which is comprised by a network of tide gauges, devices that can be used to monitor the sea level. It has been observed that Gauges close to the earthquake are able to detect the rise in the sea level that a tsunami produces. The Tide Gauge subsystem comprises of 50 tide gauges transmitting real time data through satellite communication [24].

The Bottom Pressure Recording (BPR) subsystem detects the water pressure difference that is produced from a passing tsunami. This subsystem is comprised of 12 BPR transmitting real-time data through satellite communication [25].

All the above mentioned subsystems are used to model tsunamis in three stages. The first one is the generation stage and includes the formation of the tsunami. At this stage, the water surface disturbance is transformed into a gravity wave radiating from the earthquake source. The next stage involves the propagation of the tsunami. In this stage, the tsunamis travel to all directions from the generating area, which is the epicenter of the earthquake. At this stage, the height of waves in the open ocean is $30-40 \mathrm{~cm}$ even for the most destructive tsunamis. During this stage, the wave disturbance extends through the entire water column from sea surface to the ocean sea bed. Lastly, at the Run-up, and final stage, the tsunami wave from the deep water, causes an increase in the wave height at the coast due to the coastal morphology [26]. The produced data are processed by the Japan Meteorological Agency, and alerts are forwarded to threatened countries.

Table 3. Threat Level Status Criteria

\begin{tabular}{|c|c|c|c|}
\hline \multicolumn{4}{|c|}{ Pre-run Model Scenario Results } \\
\hline \multicolumn{2}{|c|}{ ETA $<60$ mins } & \multicolumn{2}{c|}{ ETA $>60$ mins } \\
\hline EWA $(\mathrm{m})$ & Threat Status & EWA $(\mathrm{m})$ & Threat Status \\
\hline$>2$ & Warning & $>2$ & Alert \\
\hline$>0.5$ and $<2$ & Alert & $>0.5$ and $<2$ & Watch \\
\hline$>0.2$ and $<0.5$ & Watch & $>0.2$ and $<0.5$ & Watch \\
\hline
\end{tabular}

INCOIS services record earthquakes with magnitude of greater than 6.4 within the Indian Ocean and greater than 8 outside the Indian Ocean [27]. Upon such an event, experts start analyzing the event, which includes identifying the earthquake's epicenter, depth, time of origin and magnitude. Depending on the analysis, if the Estimated Wave Amplitude is greater than $0.2 \mathrm{~m}$, then the experts continue to monitor the event using the metrics Estimated Time of Arrival (ETA), Estimated Maximum Wave Amplitude (EWA). Based on the aforementioned observation and on [27] the threat is categorized as Warning/Alert or Watch (see Table 3 ). The event is being monitored and after sixty minutes have passed from the initial Earthquake, then a supplementary estimation of the Threat Level is created. Lastly, the Final conclusion for the event is taken after 120 mins of the last exceedance of $0.5 \mathrm{~m}$ in the EWA metric.

\subsection{Canadian Wildland Fire Information System (CWFIS)}

CWFIS is operating at national level since 1994 and is operated by the Canadian Fire Service (CFS). The fire brigades, federal governments, media, researchers, international organizations and the public are the main users of the CWFIS.

CWFIS is a web based system supporting several applications such as Fire Weather Maps (FWM), Fire Behavior Maps, Fire M3 Hotspots, Interactive Map, National Wildland Fire Situation Report, Monthly and Seasonal forecast maps and the National Fire Database. Most of the aforementioned applications are products of two important subsystems of CWFIS, the Canadian Forest Fire Weather Index (FWI) and the Fire Behavior Prediction (FBP) system [28, 29].

$\boldsymbol{F W I}$, which was published in 1984 ( $^{\text {th }}$ edition), is comprised of six components, all incorporated in CWFIS. These components measure the effects of wind and fuel moisture on fire behavior [29, 30, 31, 32].

More specifically, the tree components which calculate the fuel moisture based on numeric rating are the following:

- Fine Fuel Moisture Code (FFMC), measures how easy a fire can be initiated based on the moisture in fine fuels and litters found in the forest and how flammable they are in case of fire.

- Duff Moisture Code (DMC), measures the fuel consumption by calculating the average moisture in moderate duff layers and medium size object made of wood.

- Drought Code (DC), also calculates average moisture, but in deep duff layers and large wooden objects (e.g. $\operatorname{logs})$.

While the three subsystems which calculate fire behavior based on numeric rating are:

- Initial Spread Index (ISI) calculates the fire spread. To achieve this, it measures the combined effect of wind and FFMC on the rate of spread but without considering the quantities of fuels when in fact these quantities will affect the spreading of fire.

- Buildup Index (BUI) measures the total amount of fuels. To achieve this, it sums up the measurements derived by the DMC and DC.

- $\quad \boldsymbol{F} \boldsymbol{W I}$, produces fire weather forecast maps (see figure 6) based on the combined measurements of the ISI and BUI.

- Based on the FWI, the Daily Severity Rating (DSR) calculates both the effort and how difficult it will be for the fire brigade to control and eventually put out the fire. 


\section{Fire Weather Maps}

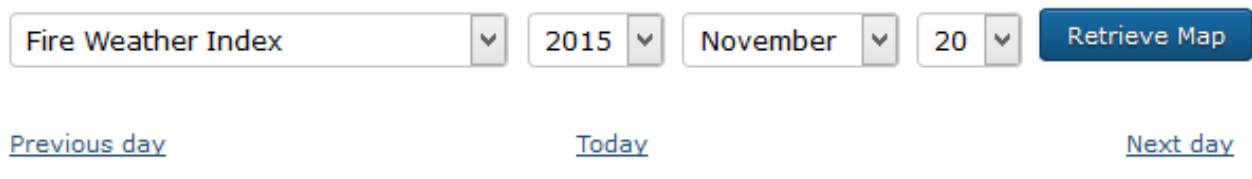

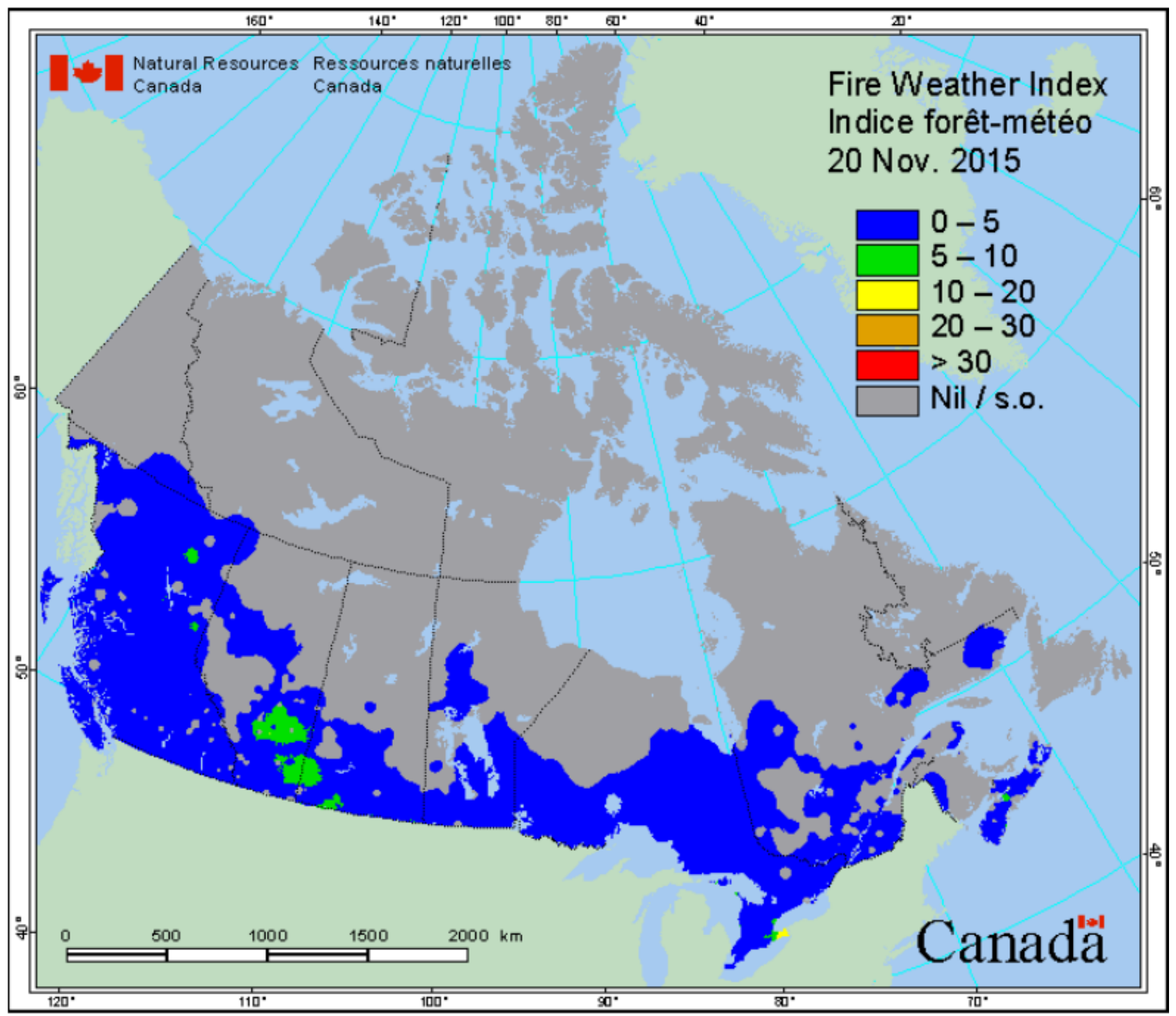

Figure 6. Fire Weather Index Maps [32]

The Fire Weather Maps (FWM) application produces short-range, medium-range and long-range forecast maps based on the FWI subsystem and the weather forecast maps provided by the Canadian Meteorological Centre (CMC). As input for the short range fire forecast (daily and 48hours maps) it uses the data derived from the weather stations under the authority of Environment Canada (around 700), the stations under the National Weather Service of the U.S.A (around 16) and the stations under the jurisdiction of three provinces of Canada; those of Nova Scotia, Quebec and Saskatchewan (around 180). In addition, forecast weather data is used as input and is provided by the network of weather stations of the Canadian Meteorological Centre (around 750) which predict the weather for a specific time and space based on two models, (1) the Model Output Statistics (MOS) and (2) the Global Environmental Multiscale for a period of forty eight hours with intervals every three hours. For the medium-range fire forecast maps (up to 14 days) it collects weather forecast data of the next 14 days from the North America Ensemble Forecast System, but due to the long range of this data it is not as accurate as the daily forecast maps. Therefore, these forecasts are mostly used to determine the upcoming trend of DC, DMC and BUI while the long-range forecast maps are produced for the next four months based on the Global Seasonal Forecast maps of CMC. Furthermore, FWM also uses as input the elevation data derived from the Digital Chart of the World and Digital Terrain Elevation Data, which is used to feed the GTOPO30 
global Digital Elevation Model (DEM), the elevation grid which is calculated based on the Digital Elevation Model (DEM), a hydrological model built by the US Geological Survey [33, 34].

One of the most important features of the CWFIS is the Fire Behavior Maps application which is a visual illustration of fire behavior forecasted on a daily basis and based on the five components of the Canadian Forest Fire Behavior Prediction (FBP) System which was published in 1992 ( $1^{\text {st }}$ edition) [31]. These components based on [35] are described below:

- Rate of Spread (ROS) calculates the speed at the head of the fire based on the ISI, BUI, the type of fuel, the state of the trees (deciduous), the height of the crown (coniferous) and the level of grasses curing.

- Total Fuel Consumption (TFC) predicts how much fuel the fire will consume in $\mathrm{Kg} / \mathrm{m}^{2}$ of ground surface on both the crowns of trees and the ground. This measurement is based on the ROS, Surface fuel Consumption (SFC) and Foliar Moisture Content (FMC).

- Head Fire Intensity (HFI) provides an intensity prediction (measured in $\mathrm{kWh} /$ meter) at the head of the fire. This measurement is based on the ROS and TFC. Based on this measurement, the Fire brigade will calculate in more accuracy the forces and methods needed to suppress the fire.

- Crown Fraction Burned (CFB), based on the BUI, ROS, FMC and SFC measurements, predicts the amount of tree crowns the fire will consume.

- Fire Type (FT) presents a generic fire description based on the CFB.

- If CFB $<10 \%$ it means that the fire only burns at the surface of the forest

- If CFB $>=90 \%$ it means that it is a continues crown fire

- If CFB between $10 \%$ and $90 \%$ it is an intermittent crown fire

Furthermore, FBP produces two sets of fire behavior measurements; the primary and secondary. The primary set consists of the individual measurement of each of the aforementioned components and is used by the CWFIS.

The second set of measurements, which is not frequently used, measures the head, flank and back fire spread distance, the flank and back fire rates of spread, the flank and back fire intensities, the elliptical fire area and perimeter, the rate of perimeter growth and the length-to-breadth ratio [35].

Fire monitoring, mapping and modeling (Fire M3) system became operational in 1998 by the CFS in collaboration with Canada Centre for Remote Sensing. Fire M3 system identifies and locates active hotspots (on a daily basis), produces reports (on daily basis, but only from May to September), measures the burned area (on a daily/annual basis) and models the behavior of the fire and the consumption of biomass.

Active fires are successfully located and monitored through the utilization of three different imagery sources:

- High resolution images acquired by the Advanced Very High Resolution Radiometer (AVHRR) of the US National Oceanic and Atmospheric Administration (NOAA),

- Low and moderate resolution images acquired by MODIS sensor of NASA and the Remote Sensing Applications Center (RSAC)

- Infrared and visible images acquired by the University of Maryland and the RSAC.

The information (e.g. reports, images, data from the internet, etc.) are shared with relevant stakeholders and are used as an input to other systems (e.g. smoke forecasting systems, etc.) [36, 37].

Interactive Map application provides information regarding the Fire Danger (Forecast), Fire Perimeter Estimation, CIFFC Priority Fires, Active Fires, Season-to date Hotspots, Fire M3 Hotspots, Forecast weather stations and reporting weather stations, in a layered structure and in a visualized manner as depicted in the figure below [38]. 


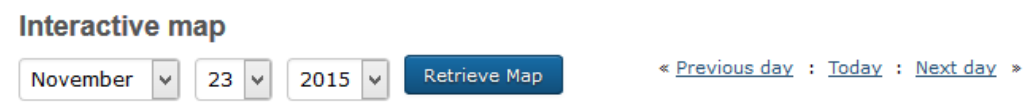

Instructions: Map Navigation

Keyboard users: When the map is in focus, use the arrow keys to pan the map and the plus and minus keys to zoom. The arrow keys will not pan the map when zoomed to the map extent.
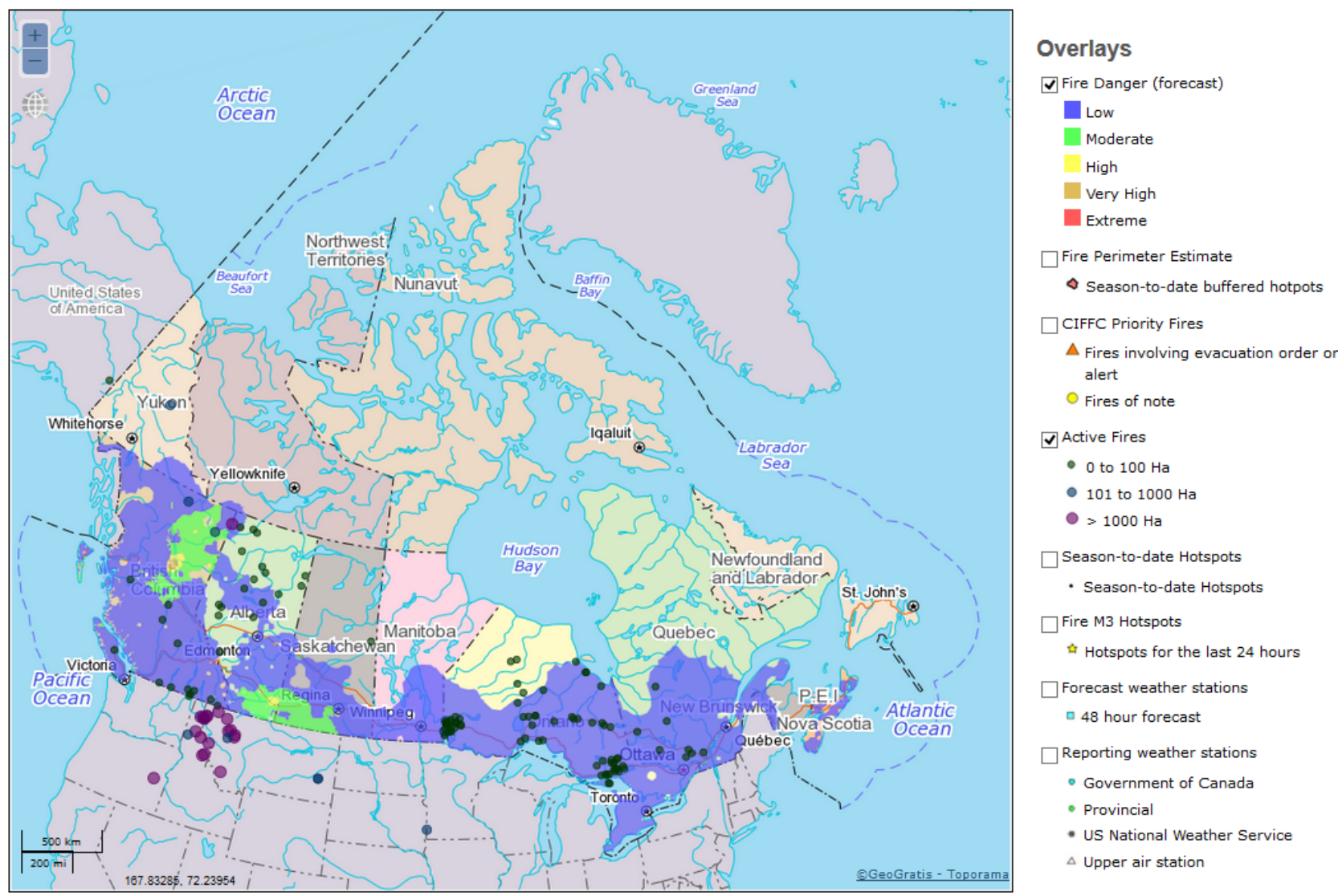

Figure 7. Interactive Map Application [38]

The Weather application can provide nine different maps for: Atmospheric Dispersion Index, Mixing Height, Pasquill - Gilford - Turner stability, Accumulated Precipitation, Relative Humidity, Temperature, Transport Wind Vector, Ventilation Index and Wind Speed respectively. All the aforementioned maps are produced by the Canadian Forest Index system on a daily basis [39].

The Fire Occurrence Prediction application can provide four different maps according to [40], which calculate the following:

- Lightning Fire Probability: the probability of a fire occurring due to a lightning strike. This measurement derives from four sub measurements based on the following probabilities: the probability of Long-continuing Current, and the following three probabilities (all of which produce their own maps) the Probability of Ignition, the Probability of Smoldering and the Probability of Arrival.

- Probability of Ignition: the probability that a lightning bolt with a long-continuing current will cause a smoldering ignition or flames in forest fuels.
- Probability of Smoldering: the probability that a smoldering ignition will evolve in a smoldering fire.

- Probability of Arrival: calculates the probability that a smoldering fire will evolve into flaming combustion.

The Monthly and Seasonal Forecasts application, an experimental product of CWFIS, produces maps that Forecast Severity Rating, Average Severity Rating, Confidence Rating and Forecast Severity Anomaly. Monthly forecast maps are produced in the beginning of every month, while the Seasonal forecast maps (four months forecast) are produced twice a year, $1^{\text {st }}$ of April and $1^{\text {st }}$ of May and only before the fire season [41].

The National Wildland Fire Situation Report application produces reports for a period of five months (May September) on a weekly basis. These reports provide information regarding the mobilization of units between provinces of Canada as well as between Canada and other countries (e.g. USA). Furthermore, it also provides a synopsis of the current week regarding new fires, burning area in total (in ha), total burned area in comparison with the average of 10 years, fire danger and the status of 
ongoing fires as well as a prognosis for the following week. Also, this application includes an archive of reports from 1998 [42].

The Historical Analysis application offers maps for Fire Weather (BUI, DMC, FWI, ISI, DC, DSR and FFMC) and Behavior (ROS, HFI, TFC and Crown Fraction Burned) normals from 1981 to 2010 (April - September). Furthermore, information (e.g. fire perimeter, location etc.) regarding fires which covered an area greater than 200 ha and occurred between 1980 and 2012 are stored in the Canadian National Fire Database (CNFDB). The data is also used for statistical analysis such as the number of fires each year, the average number of burned hectares, the reasons that caused the fires (in percentage) and more [43].

\subsection{Japan Meteorological Agency (JMA) - Warning Systems}

JMA issues warnings regarding seismic activity, tsunamis and volcanic eruptions in order to prevent and mitigate natural disasters. To achieve these actions taken by JMA are focused on monitoring, forecasting and providing timely efficient and reliable information regarding upcoming disastrous events to the respective agencies as well as to the public in order to prevent (if possible), prepare and mitigate as effectively as possible.

Around 200 seismographs and 600 seismic intensity meters are the "backbone" of the JMA's monitoring network while at the same time it is utilizing the 2912 seismic intensity meters of the National Research Institute for Earth science and Disaster Prevention (NIED) and the 777 supervised by the local governments are been used to monitor the seismic activity in Japan (see figure 8) [44].

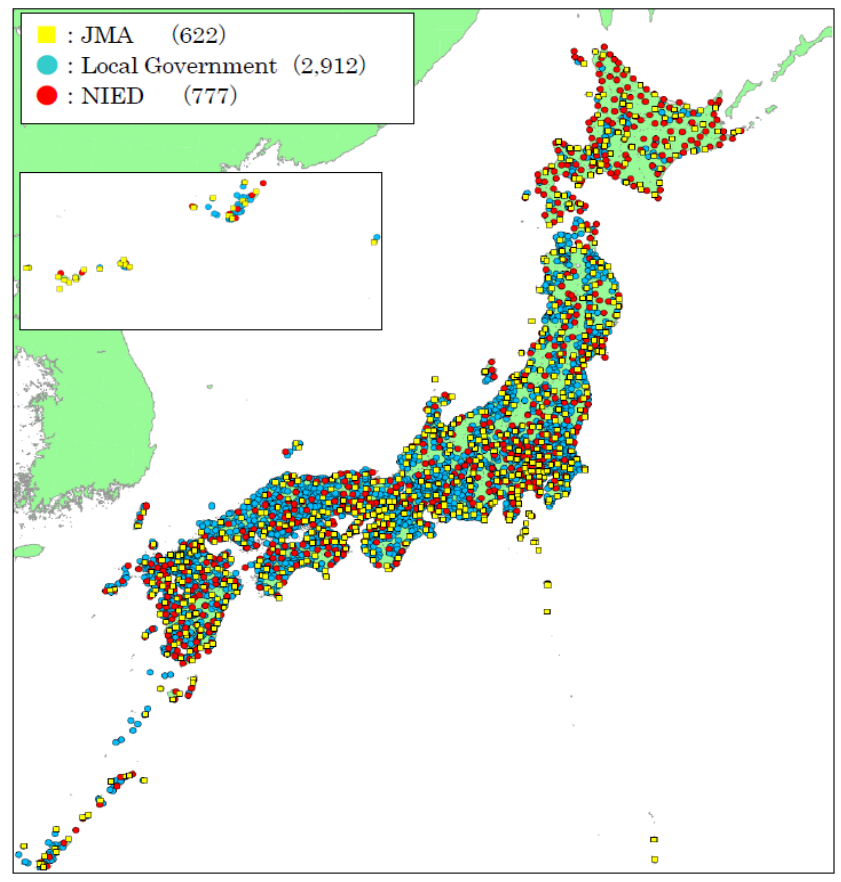

Figure 8. Monitoring Network [44]
The Earthquake Phenomena Observation System (EPOS), is the fourth generation computer system responsible for issuing the Tsunami Warnings and the Earthquake Early Warnings based on the information produced, and collected in real-time from the aforementioned monitoring network. Two EPOS are running in 24/7/365 bases, the main in Tokyo while the second is located in Osaka and is running as a backup of the first. Both run simultaneously in case the Tokyo EPOS is damaged then the Osaka backup EPOS becomes the main operational system. In the case of an earthquake, EPOS will produce information regarding the magnitude, focus and the seismic intensity while it will generate and send to all relevant stakeholders (Disaster prevention agencies) a Seismic Intensity Information report if the seismic intensity is equal or higher than 3 , in less than $1 \frac{1}{2}$ minute (in most cases in less than 1 minute). Furthermore a network of public dissemination of the relevant information through the media and/or the local authorities is activated [45].

The Earthquake Early Warning (EEW) system became operational in October 2007. This system provides timely efficient announcement of the estimated seismic intensity and expected tremor arrival time. The main goal of this system is to inform citizens and agencies for an upcoming earthquake in order to enable them to go to safety, minimizing possible damages and injuries (e.g. inform trains to slow down) $[46,47,48]$. Based on $[49,50,51]$ EEW is transmitted by various means as listed below:

- NHK television channels \& Japanese TV broadcasters

- All major mobile networks providers through SMS

- IOS 5 includes EEW notification for Japanese users

- Through radio receivers

- Through radio station equipped with EEW system such us, NHK radio, JOGV-FM etc

- Through cable TV (small fee is required)

- Internet: through the paid application/service The Last 10 Second, offered by Weathernews Inc.

Even though the JMA in collaboration with the National Research Institute for Earth Science and Disaster Prevention are constantly improving the EEW it still has four drawbacks based on [52] worth mentioning,

- Timing: locations close to the epicenter of the earthquake will not receive the EEW on time

- False alarms might occur when using information from one seismograph

- The Estimation of magnitude of large earthquakes it has limits regarding the accuracy, also it is difficult to produce EEW if more than one earthquake strikes at the same time or in few seconds from each other.

- Seismic intensity estimation has limits regarding the accuracy of the estimation when the statistical attenuation formula is used. Also there are limits regarding the prognosis of land surface amplification. 


\section{Tsunami Warning System}

Tsunami Warning system will assess the probability of a tsunami hitting the coastal areas and it will issue the relevant level warning as shown in the table below. The information issued are, the estimated height of the waves in each location separately as well as the estimated time that the tsunami will strike each location. When an earthquake occurs with magnitude equal or greater than 8 , JMA issues a warning based on the table 4 .

Table 4. Categorization of Tsunami Warnings

\begin{tabular}{|c|c|c|c|c|}
\hline \multirow[b]{2}{*}{ Category } & \multirow[b]{2}{*}{ Indication } & \multicolumn{2}{|c|}{ Estimated maximum tsunami heights } & \multirow[b]{2}{*}{ Expected damage and action to be taken } \\
\hline & & $\begin{array}{l}\text { Quantitative } \\
\text { expression }\end{array}$ & $\begin{array}{l}\text { Qualitative } \\
\text { expression }\end{array}$ & \\
\hline $\begin{array}{l}\text { Major Tsunami } \\
\text { Warning }\end{array}$ & Height is expected to be $>3 \mathrm{~m}$ & Over $10 \mathrm{~m}, 5 \mathrm{~m}$ & Huge & $\begin{array}{l}\text { Actions: Relocate to higher ground or to } \\
\text { tsunami evacuation buildings instantly }\end{array}$ \\
\hline Tsunami Warning & $\begin{array}{l}\text { Height is expected to be up to } \\
\qquad 3 \mathrm{~m}\end{array}$ & $3 \mathrm{~m}$ & High & $\begin{array}{c}\text { Actions: Evacuate from coastal or river areas } \\
\text { to higher ground or to tsunami evacuation } \\
\text { buildings }\end{array}$ \\
\hline Tsunami Advisory & $\begin{array}{l}\text { Height is expected to be up to } \\
\qquad 1 \mathrm{~m}\end{array}$ & $1 \mathrm{~m}$ & $\mathrm{~N} / \mathrm{A}$ & $\begin{array}{l}\text { Actions: (a) People have to get out of the sea } \\
\text { and (b) leave coastal areas }\end{array}$ \\
\hline
\end{tabular}

Volcanic Warning System

Japan has around 110 active volcanoes which are being constantly monitored. In 1888 for the first time a seismograph was installed near an active volcano (in Kagoshima weather station), and that was the beginning of the network currently deployed in Japan for monitoring all active volcanos in 24/7 basis. After 23 years, in 1911 the first observatory was created in Asamayana and during the early 60s JMA worked on establishing a nationwide volcano observation system which will constantly monitor specific active volcanos (17 at the time) while at the same time mobile units monitored the rest of the volcanos. During the mid-60s JMA started providing information to the public [53].

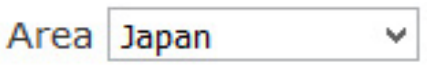

\section{Current Volcanic Warnings (Japan)}

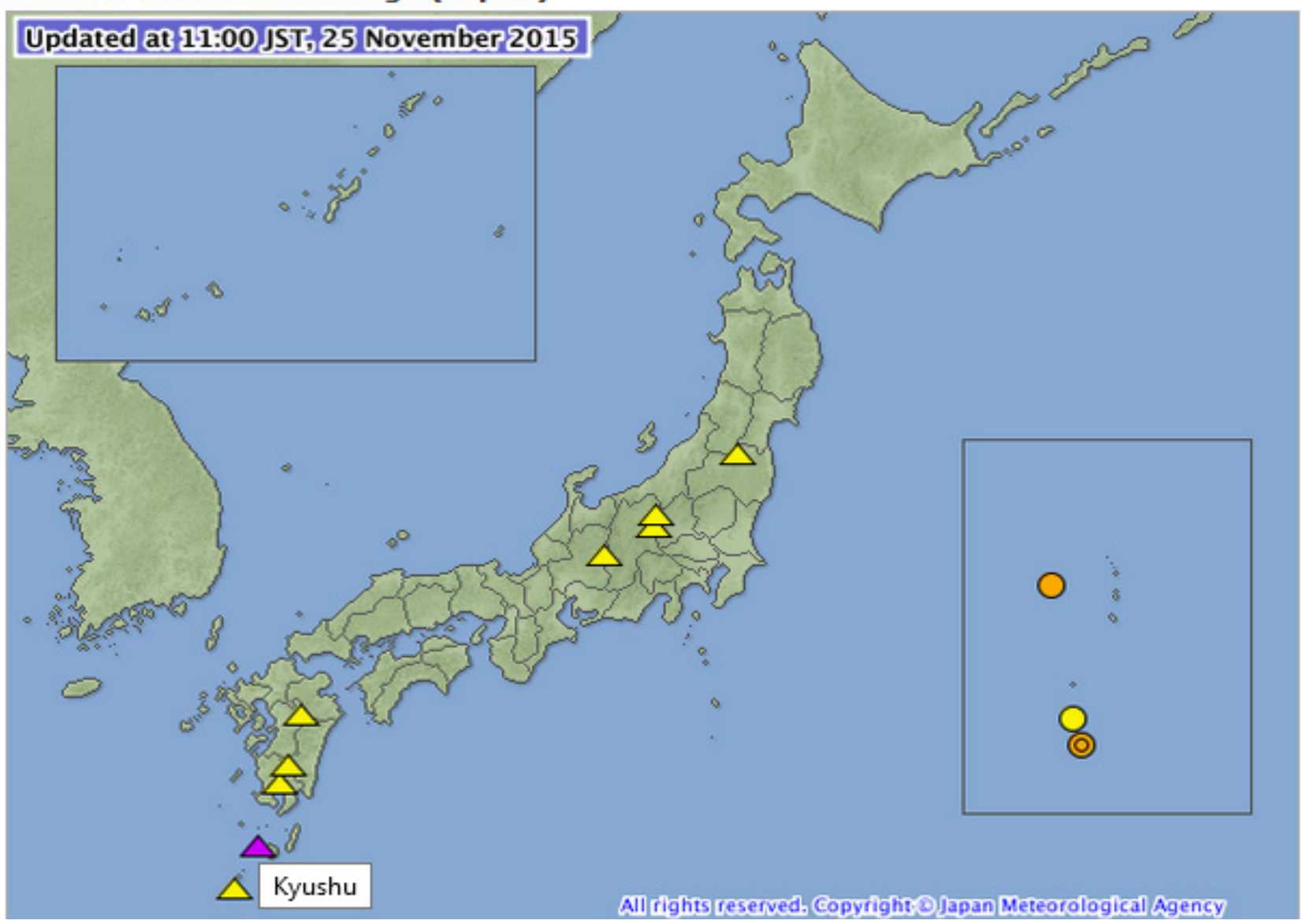

Figure 9. Current Volcanic Warnings-Web Interface 


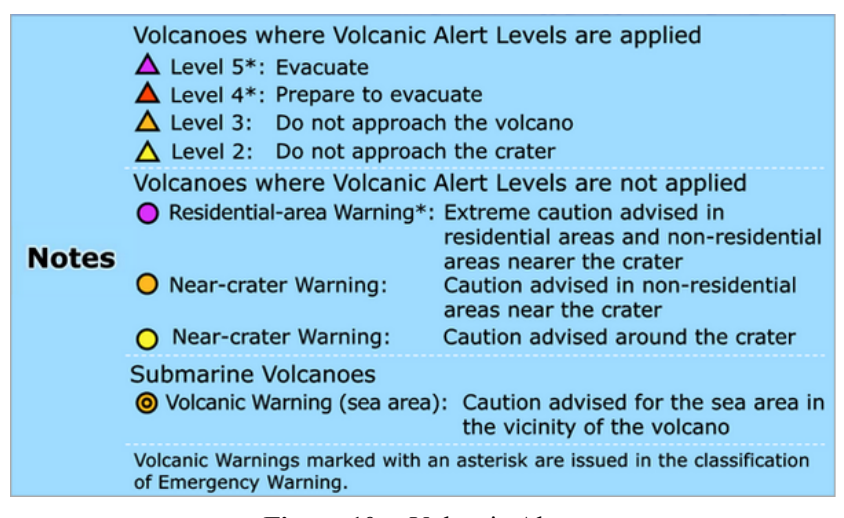

Figure 10. Volcanic Alerts

The Volcano Observation and Information Centers (VOIC) in four locations, Tokyo, Sendai, Fukuoka and Sapporo, were established in 2002. The main goal of these centers was to monitor and collect data from all the equipment (e.g. seismographs) located near all active volcanos (47 from 2009). In December 2007 JMA's system for volcanic warnings became operational in order to issue Volcanic warnings/forecasts to enhance the prevention and mitigation of upcoming hazards for, Japan and the seven following locations/prefecture/regions, Hokkaido, Tohoku, Kanto/Chubu, Izu/Ogasawara, Chugoku, Kyushu and Okinawa through the web interface of the system (see figure 9). To achieve these JMA is monitoring the 110 active volcanoes in Japan as depicted in figure $11[53,54]$.

The triangle and circle spots on the interactive map (above) are indicating the level of threat in locations that the alerts are apply and in locations that the alerts are not apply respectively (see figure 10).

The Volcanic warnings/forecasts are divided into three (3) categories, based on the location of the volcano and the level of severity, as described in table 5.

Table 5. Volcanic Warning Levels $[53,54]$

\begin{tabular}{|c|c|c|}
\hline $\begin{array}{c}\text { Abbreviated } \\
\text { Term }\end{array}$ & Target Area & Levels \\
\hline \multirow{2}{*}{ Warning } & Residential Area & \begin{tabular}{c} 
Level 5: Evacuate \\
\cline { 3 - 3 }
\end{tabular} \\
\hline \multirow{2}{*}{$\begin{array}{c}\text { Near-crater } \\
\text { Warning }\end{array}$} & $\begin{array}{c}\text { Nonrepare to } \\
\text { (Nearidential areas }\end{array}$ & $\begin{array}{c}\text { Level 3: Do not } \\
\text { Approach the Volcano }\end{array}$ \\
\cline { 2 - 3 } & Around the crater & $\begin{array}{c}\text { Level 2: Do not approach } \\
\text { the crater }\end{array}$ \\
\hline Forecast & Inside the crater & Level 1: Normal \\
\hline
\end{tabular}

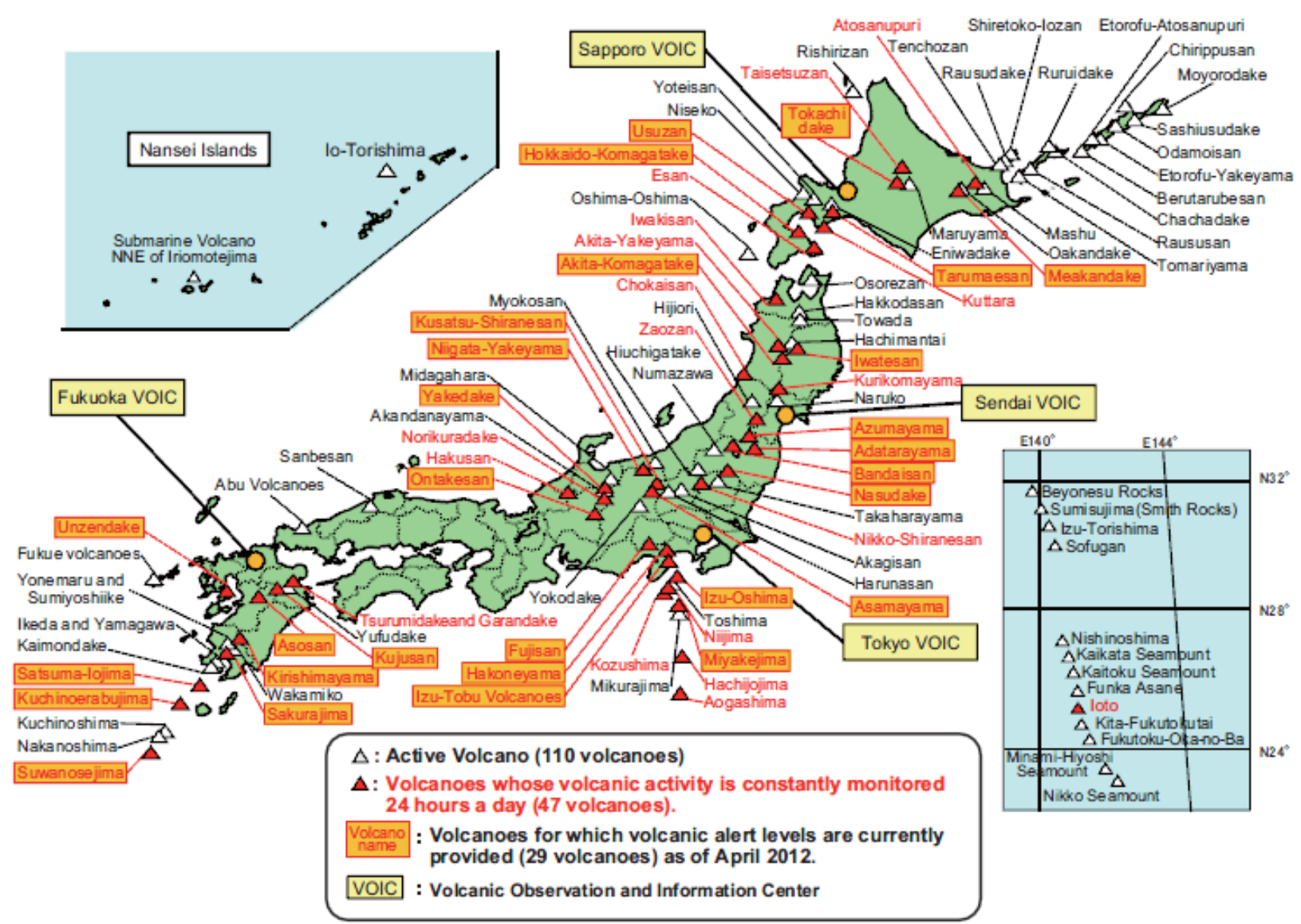

Figure 11. Active volcanoes \& VOICs in Japan [53] 


\section{Conclusions}

The rising number of disasters has been a wake-up call for the European institutions; their reaction - on the basis of the Lisbon Treaty, under which the EU is called upon to get organized at a multinational level in order to deal with major catastrophes - has been vigorous and swift. The question, however, is whether it is possible to coordinate with the mosaic of responsibilities and competences for crisis management, and the generation of synergies. Such actions require an infrastructure that supports the transparent data collection, distribution and sharing as well as communication. In this frame, Information Systems are an important tool for all Public Protection and Disaster Relief agencies involved that undoubtedly can assist the effectiveness of handling a disaster, either as preventive or post disaster management.

This report has demonstrated both the crucial aforementioned functionalities that Information Systems accommodate for, a study that has not been carried out in the past. In the cases of disasters, be natural or man-induced, preparedness is the advantage that makes the difference to the response and efficiency. Hence, systems like Global Flood Awareness System (GloFAS) or Global Disaster and Coordination System (GDACS) or European Flood Awareness System (EFAS) and Volcanic Warning system of JMA are examples of monitoring and early warning systems that can save lives. Other systems dedicated to early stage and post disaster management such as Cisco Open Platform for Safety and Security (COPSS) or The European Forest Fire Information System (EFFIS), the Canadian Wildland Fire Information System (CWFIS) or Indian Ocean Tsunami Warning System (INCOIS) and Earthquake/Tsunami warning system support efficient decision making that lead to minimization of the disaster effects. Note that the reported Information Systems are a selection of the multi-disciplinary disaster management field.

In all cases, it is clear that Information Systems are a key piece to the mosaic of the disaster resilience, preparedness and anticipation but also of the post crisis management by providing the information required for efficient coordination and decision making procedures.

\section{Acknowledgements}

We would like to acknowledge that the study leading to these results has received funding from the European Union Seventh Framework Programme (FP7/2007-2013) under grant agreement $n^{\circ} 607832$ (project SecInCoRe). The text reflects the authors' views. The European Commission is not liable for any use that may be made of the information contained therein.

\section{REFERENCES}

[1] Joint Research Centre, "About EFFIS-Brief History" Online available from:

http://forest.jrc.ec.europa.eu/effis/about-effis/brief-history

[2] Joint Research Centre, "About EFFIS" Online available from: http://forest.jrc.ec.europa.eu/effis/about-effis/

[3] Joint Research Cenrte, "Applications" Online available from: http://forest.jrc.ec.europa.eu/effis/applications/

[4] Joint Research Cenrte, "Fire Danger Forecast" Online available from: http://forest.jrc.ec.europa.eu/effis/about-effis /technical-background/fire-danger-forecast/

[5] Joint Research Centre, "Active Fire Detection" Online available from:

http://forest.jrc.ec.europa.eu/effis/about-effis/technical-back ground/active-fire-detection/

[6] Joint Research Centre, "Rapid Damage Assessment", Online available from:

http://forest.jrc.ec.europa.eu/effis/about-effis/technical-backgro und/rapid-damage-assessment/

[7] Joint Research Centre, "Fire Damage Assessment," JRC, Online available from:

http://forest.jrc.ec.europa.eu/effis/about-effis/technical-back ground/fire-damage-assessment/

[8] Joint Research Centre, "European Fire Database" JRC, Online] available from: http://forest.jrc.ec.europa.eu/effis/ab out-effis/technical-background/european-fire-database/

[9] Joint Research Centre, "Under development" JRC, Online available from:

http://forest.jrc.ec.europa.eu/effis/about-effis/technical-back ground/under-development/

[10] C.A. Eklund, M. Hazlinger, E. Sprokkereef, M.G. Padilla, R.J. Garcia, J. Thielen, P. Salamin, F. Pappenberger, "European Flood Awareness System - now operational," Geophysical Research Abstracts, vol. 15, no. EGU2013-11796, 2013.

[11] D. Demeritt, S. Nobert, H. L. Cloke, F. Pappenberger, "The European Flood Alert System and the communication, perception, and use of ensemble predictions for operational flood risk management," Hydrological Processes, vol. 27, no. 1, pp. 147-157, 2013.

[12] J.C. Bartholmes, J. Thielen, M.H. Ramos, S.Gentilini, "The european flood alert system EFAS - Part 2: Statistical skill assessment of probabilistic and deterministic operational forecasts," Hydrol. Earth Syst. Sci., vol. 13, pp. 141-153, 2009.

[13] Z. Zajac, B.R. Romero, F.A. Hirpa, V. Ntegeka, P. Salamon, J. Thielen, P. Burek, H. Beck, "Recent advances in the Global Flood Awarness System (GloFAS)," Geophysical Research Abstracts, vol. 16, no. EGU2014-12182-1, 2014.

[14] L. Alfieri, P. Burek, B. Krzeminski, D. Muraro, J. Thielen, F. Pappenberger, "GloFFAS-global ensemble streamflow forecasting and flood early warning" Hydro. Earth Syst. Sci, vol. 17, pp. 1161-1175, 2013

[15] European Commission, OCHA, UNOSAT, "About GDACS" Online available from: http://portal.gdacs.org/about

[16] V. Bohl, "Presentaiton of Virtual on-site operation 
coordination center", Online available from: http:/www.wcoomd.org/en/topics/facilitation/activitiesand-pogrammes/ /media/WCO/Public/Global/PDF/Topics/F acilitation/Activities\%20and\%20Programmes/Natural\%20Di saster/Virtual_osocc1.ashx.

[17] European Commission, OCHA, UNOSAT, "GLOBAL DISASTER ALERT AND COORDINATION SYSTEM," Online available from:

http://vosocc.unocha.org/Documents/att36104_smcewj.pdf

[18] Joint Research Centre, "Global Disaster Alert and Coordination System (GDACS)", Online available from: http://lunar.jrc.it/critech/Default.aspx?Tabid=58

[19] CISCO, "CISCO Urban Security Design Guide", Online available from:

http://www.cisco.com/c/en/us/td/docs/solutions/Verticals/Go vernment/Urban_Security_DG/Urban_Secure_DG.pdf

[20] CISCO, "Cisco Open Platform for Safety and Security: Understand the Mobile Force Architecture Building Block", Online available from:

http://www.cisco.com/web/strategy/docs/gov/COPSSMobile Force_wp.pdf

[21] Osborne,H. 2004 "Indian Ocean earthquake and tsunami: Facts about the Boxing Day disaster", Online available from: http://www.ibtimes.co.uk/2004-indian-ocean-earthquake-tsu nami-facts-1480629

[22] UNESCO, "Indian Ocean Tsunami Warning System up and running", Online available from: http://portal.unesco.org/en/ ev.php-URL_ID=33442\&URL_DO=DO_TOPIC\&URL_SE $\mathrm{CTION}=201 . \mathrm{html}$

[23] Indian Tsunami Early Warning System, "About Seismic Subsystem", Online available from:

http://www.tsunami.incois.gov.in/ITEWS/seismic.jsp

[24] Indian Tsunami Early Warning System, “About Tide Gague Subsystem", Online available from:

http://www.tsunami.incois.gov.in/ITEWS/tideguage.jsp

[25] Indian Tsunami Early Warning System, "About BPR Subsystem", Online available from:

http://www.tsunami.incois.gov.in/ITEWS/doars.jsp

[26] Indian Tsunami Early Warning System, "Tsunami Modeling”, Online available from: http://www.tsunami.incois.gov.in/ITEWS/tsunamimodeling.j $\mathrm{sp}$

[27] Indian Tsunami Early Warning System, "ITEWC Standard Operating Procedure (SOP)", Online available from: http://www.tsunami.incois.gov.in/ITEWS/dss_sop.jsp

[28] B.S. Lee, M.E. Alexander, B.C. Hawkes, T.J. Lynham, B.J. Stocks, P. Englefield, "Information Systems in support of wildland fire management decision making in Canada", Computers and Electronics in Agriculture, Vol. 37, Issue 1-3, pp. 185-198, 2002

[29] A. Camia, J. San Miguel-Ayanz, "Remote sensing inputs to forest fire danger rating", Proceedings of the $5^{\text {th }}$ International Workshop on Remote sensing and GIS Applications to Forest Fire Management: Fire Effects Assessment: pp 1-7, Universidad de Zaragoza, Spain, 2005

[30] Natural Resources Canada - Canadian Wildland Fire Information System, "Canadian Forest Fire Weather Index
(FWI) System”, Online available from: http://cwfis.cfs.nrcan.gc.ca/background/summary/fwi

[31] Natural Resources Canada - Canadian Wildland Fire Information System, "Canadian Forest Fire Danger Rating System (CFFDRS)", Online available from: http://cwfis.cfs.nrcan.gc.ca/background/summary/fdr

[32] Natural Resources Canada - Canadian Wildland Fire Information System, "Fire Weather Maps", Online available from: http://cwfis.cfs.nrcan.gc.ca/maps/fw?type=fwi

[33] Natural Resources Canada - Canadian Wildland Fire Information System, "Canadian Forest Fire Weather Index (FWI) System”, Online available from: http://cwfis.cfs.nrcan.gc.ca/background/dsm/fwi

[34] K. Anderson, E. Carr, P. Englefield, J. Little, R. Suddaby, "Extended-range Fire Weather Products with the Canadian Wildland Fire Information System", Canadian Forest Service, Online available from:

https://www.ualberta.ca/ wildfire/2010/PDFs/Kerry\%20And erson.pdf

[35] Natural Resources Canada - Canadian Wildland Fire Information System, "Canadian Forest Fire Behavior (FBP) System", Online available from:

http://cwfis.cfs.nrcan.gc.ca/background/summary/fbp

[36] Natural Resources Canada - Canadian Wildland Fire Information System, "Fire M3 Hotspots", Online available from: http://cwfis.cfs.nrcan.gc.ca/maps/fm3?type=tri

[37] Natural Resources Canada - Canadian Wildland Fire Information System, "Fire Monitoring, Mapping, and Modeling (Fire M3)", Online available from: http://cwfis.cfs.nrcan.gc.ca/background/summary/fm3

[38] Natural Resources Canada - Canadian Wildland Fire Information System, "Interactive Map", Online available from: http://cwfis.cfs.nrcan.gc.ca/interactive-map

[39] Natural Resources Canada - Canadian Wildland Fire Information System, "Weather Maps", Online available from: http://cwfis.cfs.nrcan.gc.ca/maps/wx

[40] Natural Resources Canada - Canadian Wildland Fire Information System, "Fire Occurrence Prediction Maps", Online available from: http://cwfis.cfs.nrcan.gc.ca/maps/fop?type=lfp

[41] Natural Resources Canada - Canadian Wildland Fire Information System, "Monthly and Seasonal Forecasts", Online available from: http://cwfis.cfs.nrcan.gc.ca/maps/fore casts

[42] Natural Resources Canada - Canadian Wildland Fire Information System, "National Wildland Fire Situation Report", Online available from: http://cwfis.cfs.nrcan.gc.ca/r eport

[43] Natural Resources Canada - Canadian Wildland Fire Information System, "Canadian National Fire Database", Online available from:

http://cwfis.cfs.nrcan.gc.ca/ha/nfdb?type=poly\&year=9999

[44] Japan Meteorological Agency - Monitoring of Earthquakes, Tsunamis and Volcanic Activity, "Monitoring of Earthquakes and Provision on Information", Online available from: http://www.jma.go.jp/jma/en/Activities/earthquake.html

[45] M.M. Resch, X. Wang, W. Bez, E. Focht, H. Kobayashi, 
"Sustained Simulation Performance 2012: Proceedings of the joint Workshop on High Performance Computing on Vector Systems”, Springer, Germany, pp 81-82, 2012

[46] Japan Meteorological Agency - Monitoring of Earthquakes, Tsunamis and Volcanic Activity, "Earthquake Early Warning System", Online available from: http://www.jma.go.jp/jma/en/Activities/earthquake.html

[47] T. Koizumi, "JMA Tsunami Warning Services", Online available from: http://webcritech.jrc.ec.europa.eu/tsunami/Portals/0/pdf/JM A_Earthquake\%20and\%20Tsunami.pdf

[48] Japan Meteorological Agency, "What is an Earthquake Early Warning?", Online available from: http://www.jma.go.jp/jma/en/Activities/eew1.html

[49] M. Gurman, "iOS 5 includes early earthquake warning notifications for Japanese iPhone users", Online available from:

http://9to5mac.com/2011/08/21/ios-5-includes-early-earthqu ake-warning-notifications-for-japanese-iphone-users/

[50] M. Yamada, "Earthquake Early Warning in Japan", Online available from: http://www.eqh.dpri.kyoto-u.ac.jp/ masumi/ eq/ews.htm

[51] Nikkei Technology Tech \& Industry Analysis from Japan/Asia online, "Weathernews Launces Earthquake Early Warning Service for Private Customers", Online available from:

http://techon.nikkeibp.co.jp/english/NEWS_EN/20071016/1 40701/

[52] Japan Meteorological Agency - Earthquake Early Warning System, "Limitations of the Earthquake Early Warning", Online available from:

http://www.jma.go.jp/jma/en/Activities/eew3.html

[53] H. Yamasato, J. Funasaki, Y. Takagi, “The Japan Meteoroidal Agency's Volcanic Disaster Mitigation Initiatives", Technical Note of the National Research Institute for Earth Science and Disaster Prevention, No 380, 2013

[54] Japan Meteorological Agency - Monitoring of Earthquakes, Tsunamis and Volcanic Activity, "Volcanic Disaster Mitigation", Online available from: http://www.jma.go.jp/jma/en/Activities/earthquake.html 